\title{
The Stability of Laser Hardening Structures to Softening During Heating
}

\author{
Andrey Brover ${ }^{1,}$, Galina Brover $^{1}$, Olga Moysova $^{2}$, and Valeriya Yankovskaya ${ }^{3}$ \\ ${ }^{1}$ Don State Technical University, Physical and Applied Materials Science Department, Gagarin Sq.,1, \\ Rostov-on-Don, Russia, 344000 \\ ${ }^{2}$ Don State Technical University, Scientific-Technical Translation Department, Gagarin Sq.,1, \\ Rostov-on-Don, Russia, 344000 \\ ${ }^{3} \mathrm{Kiev}$ College of Mechanics and Technology, Metallurgy and Materials Science Department, Kharkiv \\ Hwy., 15, Kiev, Ukraine, 02090
}

\begin{abstract}
Structural and phase changes occurring in laser-hardened steels after tempering at different temperatures are considered. It is shown that the optimization of laser processing and subsequent tempering allows to increase the heat resistance of steels $50-120^{\circ} \mathrm{C}$ by maintaining a high density of defects in the crystal structure and appearance of the uniform allocation of dispersed carbide particles. It is established that for the laserirradiated metal, from the energy point of view, it is not the formation of $\varepsilon$ carbide during tempering, but the deposition of carbon atoms and alloying elements on structural imperfections with further formation of carbides according to the scheme: carbon in solid solution $\rightarrow$ carbon associated with defects $\rightarrow$ carbide on defects of the crystal structure.
\end{abstract}

\section{Introduction}

One of the main characteristics of steels, especially tool steels, is heat resistance, which has a decisive influence not only on the change in strength properties during operation, but also on such indicators as crumple resistance, wear resistance, heat resistance, etc. [1-10]. Determination of the resistance of structures obtained as a result of processing with highly concentrated energy flows to softening when heated to different tempering temperatures makes it possible to reliably differentiate the methods of surface hardening of steels by the temperature areas of operation of products of various functional purposes.

The achievement of high concentration inhomogeneity and saturation of solid solutions with carbon atoms and alloying elements, high density of defects in the crystal structure during laser processing create prerequisites for increasing the heat resistance of the hardened metal. Heating during tempering of the irradiated steel leads to the formation of a large number of dispersed matrix allocations, which increase the mechanical characteristics of the metal.

* Corresponding author: brover@mail.ru 


\section{Research methods}

In this work, for the purposes of surface hardening of materials, pulsed laser equipment "Kvant-18" was used. Changes in the radiation energy (10-30 J), the degree of beam defocusing $(4-10 \mathrm{~mm})$, and the duration of the radiation pulse from $1 \cdot 10^{-3}$ to $9 \cdot 10^{-3} \mathrm{~s}$ allowed us to change the radiation power density in the range $\left(60-150 \mathrm{MW} / \mathrm{m}^{2}\right)$.

The samples were irradiated on materials of various chemical compositions (further marking in accordance with the German standard (DIN), highlighted in bold.

The structure of the alloys after laser treatment was studied using Neophot-21 microscopes. The thin structure of the irradiated materials was studied by scanning probe microscopy.

Diffractometer DRON-3 was used for X-ray diffraction studies. The X-ray line profiles were captured in continuous recording mode at a speed of $1 \mathrm{deg} / \mathrm{min}$ in filtered $\mathrm{Fe}_{\mathrm{K \alpha}}$ radiation with the intensity recorded by a scintillation counter. The hardness measurements were carried out on a PMT-3 microhardness meter with a load of $0,49 \mathrm{~N}$. When determining the heat resistance of the metal, a standard test method was used, that is, the hardness of the irradiated material was measured after a three-hour exposure at different heating temperatures.

\section{Discussion of results}

It is established that the nature of the change in hardness during heating of the hardened sections depends on the chemical composition and irradiation modes of the steel.

X-ray diffraction and durometric analysis of laser-irradiated steels showed that, as seen in Fig.1, structure-sensitive lattice parameters of the material, such as the width of the diffraction lines reflex (211) $\alpha$, and micro-hardness of the metal are interrelated and depend on the dislocation density, microscopic strains in the crystal lattice, the dispersion of the structural components. The assessment of the degree of influence of these factors on the width of martensite reflexes showed that the main contribution is made by the density of dislocations. At the same time, as can be seen in Fig.1, the greatest broadening of the diffraction lines of the reflex (211) $\alpha$, for example, for irradiated steel 1.3343, and the highest microhardness are observed in the region of dispersion hardening temperatures $\left(550-570^{\circ} \mathrm{C}\right)$.

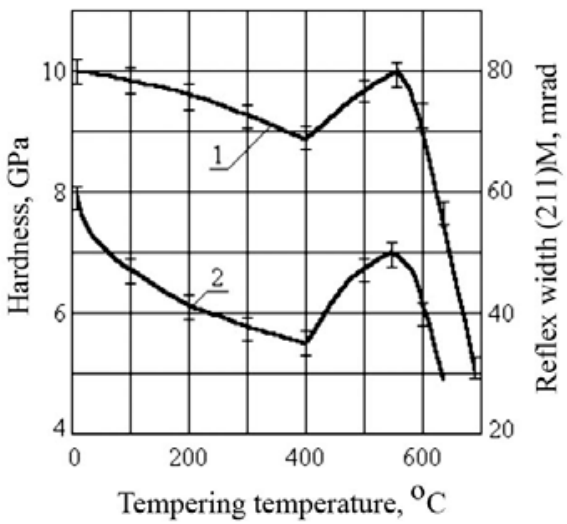

Fig. 1. Dependency hardness of irradiated steel 1.3202 (1) and reflex width (211) martensite laser hardened (2) from the tempering temperature. 
This is confirmed by the results of the studies presented in Fig.2. For this purpose, an array of measurements of the hardness of laser-irradiated surface layers of steel with different dislocation densities after heating to different temperatures was processed in the «Statistica» program. On this basis, a simulation map was built, the peculiarity of which is that it shows a given area of change of variables, each of the values of which in this area is displayed by a certain geometric element.

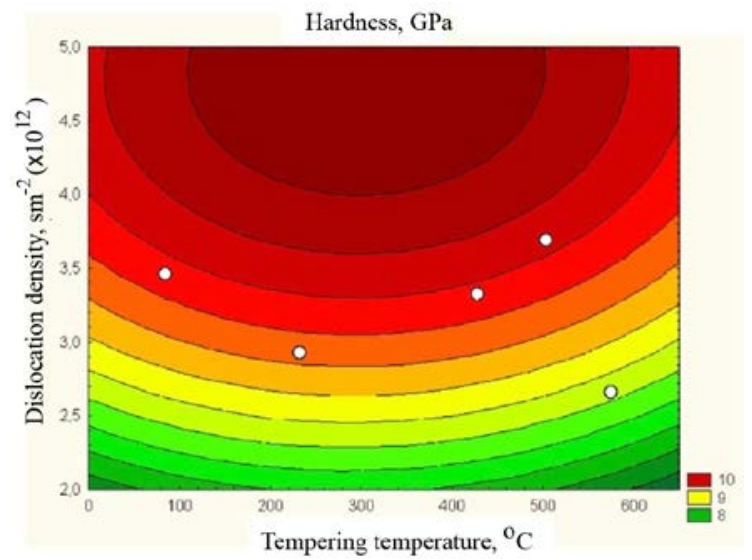

Fig. 2. Map of simulation of the hardness distribution of irradiated steel $\mathbf{1 . 3 3 4 3}$ at different tempering temperatures and dislocation density in martensite.

The observed effect of increasing the hardness and broadening of the X-phase diffraction lines of the laser-irradiated metal in the region of heating temperatures (550$570^{\circ} \mathrm{C}$ ) can be explained by the formation of elastic deformation fields and zones of local plastic deformation around the particles of the released carbide phase, which cause an increase in the density of dislocations [11-19].

Electron microscopic studies have shown that in the region of the peak of hardening in the irradiated metal, the maximum density of dispersed carbides is observed (Fig.3). An increase in the tempering temperature above $550^{\circ} \mathrm{C}$ leads to coagulation of the precipitates and a decrease in the hardness of the irradiated steel.

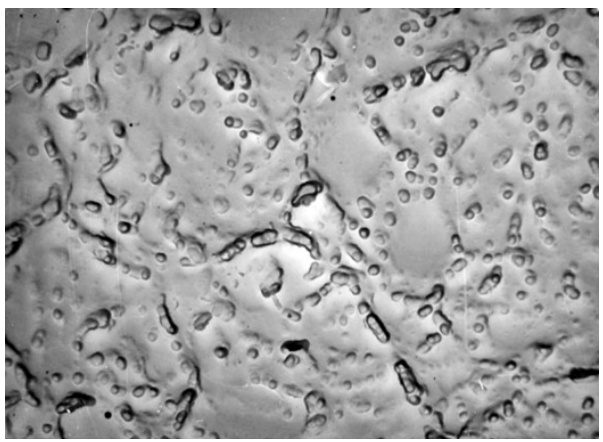

Fig. 3. Structure of irradiated steel $\mathbf{1 . 3 3 4 3}$ after tempering at $500^{\circ} \mathrm{C}$ (carbon replica).

These processes provide an increase in the heat resistance of the irradiated metal by 50$100^{\circ} \mathrm{C}$. It should be noted that the behavior of hardness during tempering of steels is determined both by hardening processes caused by precipitation of highly dispersed carbide phases and softening caused by relaxation of distortions of the martensite structure [8]. In this regard, when analyzing the obtained curves of the change in the hardness of irradiated steels, in addition to the two-phase decomposition of martensite and precipitation of 
carbides, in the presence of a high dislocation density, the possibility of polygonization and recrystallization processes in the zones of laser treatment was taken into account.

It is established that the relaxation of the martensitic lattice distortions has the greatest influence on the bulk-hardened metal, and in the laser-treated metal the role of the highly dispersed phase, which distorts the structure of the $\alpha$-solid solution. The contribution of relaxation processes increases with an increase in the tempering temperature and leads to a decrease in the width of the $\alpha$-phase reflexes and the density of defects in the crystal structure. At the same time, the density of dislocations in laser- hardening martensite remains higher than the density of dislocations in the $\alpha$-phase of the bulk-heat-treated metal.

Let us consider the regularities in the course of changing the hardness during tempering of steels, taking into account the achieved structural states of the main phases and the kinetics of the release of strengthening components.

First of all, the high hardness of the structures of laser hardening after tempering is associated with the inheritance of the increased dispersion of the structure and the density of dislocations of the $\gamma$ - and $\alpha$-phases obtained by high-speed laser processing. Under these conditions, it is preferable not to form $\varepsilon$-carbide when heating laser-hardened steels, but to deposit carbon atoms and alloying elements on structural imperfections. From the thermodynamic point of view, this process is possible and preferable because of the low binding energy of the carbon atoms in the $\varepsilon$-carbide lattice $(0,27 \mathrm{eV})$ compared to the interaction energy of the impurity atom with the lattice imperfections $(0,5-1,0 \mathrm{eV})$ for the impurity atom in the dislocation force field.

Thus, the carbide formation during the tempering of irradiated steels, apparently, occurs according to the scheme: carbon in solid solution $\rightarrow$ carbon associated with defects $\rightarrow$ carbide on defects of the crystal structure.

With a further increase in the tempering temperature, the oriented separation of the carbide phase in the hardened layer occurs, with its localization on the shear lines formed by laser irradiation under the action of thermal stresses, and the formation of a texture of dispersed precipitates (Fig.4) with a size of 2-10 nm.

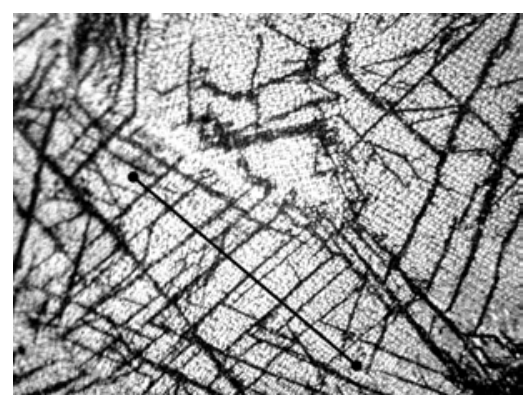

a

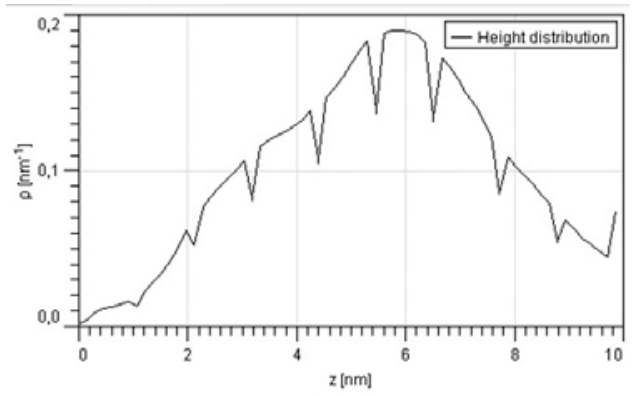

b

Fig. 4. The structure of the laser-hardened steel 1.3343 after heating $550^{\circ} \mathrm{C}$ : optical microscopy (a); distribution of surface profile heights (b).

It can be concluded that the effect of laser hardening also leads to a slowdown in the decay of martensite, the main reason for which is the stable existence of carbon atom atmospheres on dislocations at higher temperatures than is possible with bulk hardening.

It should be noted that in the irradiated zones, in addition to martensite and dispersed carbides, there is an increased amount of residual fragmented austenite (25-60\%), characterized by the presence of deformation defects in the lattice of the packaging. The 
presence of residual austenite is confirmed by the results of X-ray diffraction analysis, shown in Fig.5.

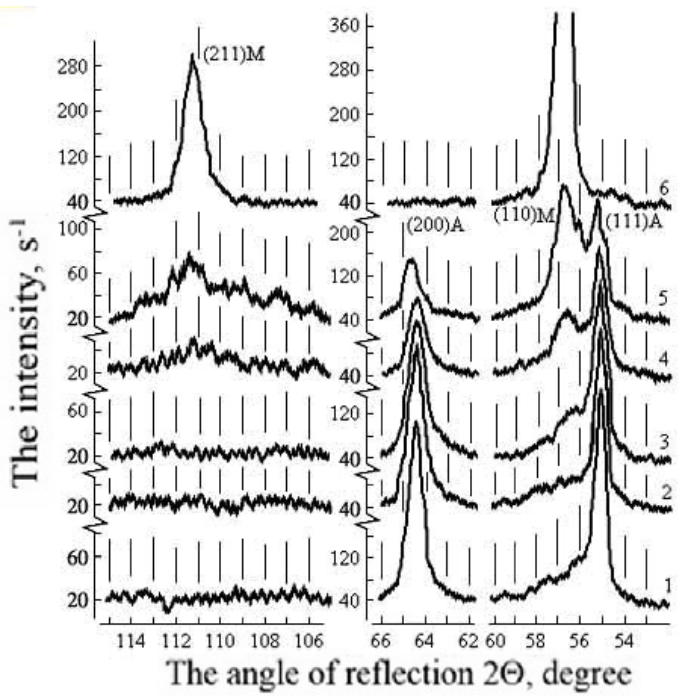

Fig. 5. Fragments of diffraction patterns of laser-hardened steel 1.2379: 1 - before heating; 2 - heating $200^{\mathbf{0}} \mathrm{C} ; 3-300^{\circ} \mathrm{C} ; 4-500^{\circ} \mathrm{C} ; 5-550{ }^{\circ} \mathrm{C} ; 6-600^{\circ} \mathrm{C}$.

It is noted that the X-ray images of the irradiated zones show an anomalous ratio of the intensity of the reflexes (111) and (200), which is characteristic of the textured metal) austenite and the increase in the intensity of the reflex (200) under irradiation of steels 1.2379, 1.2379. Despite this, the hardness of laser tempering structures on steel $\mathbf{1 . 2 3 7 9}$ is higher compared to bulk tempering structures. This is due to the formation of an unusual structure and properties of a fragmented $\gamma$-phase with a large number of deformation defects in the packaging under the conditions of high-speed laser processing.

As can be seen, in the irradiated zones on alloy steels, the high hardness is maintained up to heating temperatures of more than $600^{\circ} \mathrm{C}$.

\section{Conclusion}

Pulsed laser treatment of steels can increase the hardness of the irradiated areas to 8$11,5 \mathrm{GPa}$, heat resistance by $50-120^{\circ} \mathrm{C}$, which contributes to improving the performance properties of hardened products.

The main reasons for the increase in operational properties are the features of the structural state of the irradiated metal: fragmented structure of the main phases; incompleteness of homogenization processes with partial or complete dissolution of excess phases; increased density of defects in the crystal structure.

The effect of laser tempering is reduced to slowing down the decay of martensite, the main reason for which is the increased segregation of carbon on dislocations and the stable existence of atmospheres at higher temperatures than is possible with bulk tempering. In this case, the release of laser tempering structures can occur without the appearance of a metastable $\varepsilon$-carbide at the initial stage. It becomes possible to increase the complex properties of the irradiated metal due to the multiple formation of nanoscale secretions on the dislocations during thermal exposure, that is, due to nanoprecipitation. 
The texture effects observed in laser-hardened steels in austenite or martensite persist when heated to high tempering temperatures and lead to anisotropy of properties, in particular, to a significant reduction in the coefficient of friction.

Optimization of the laser processing and subsequent tempering modes makes it possible to increase the contribution to the hardening of the metal of both a high density of defects in the crystal structure and the appearance of a uniform separation of dispersed carbide particles. High hardness in the irradiated zones on alloy steels is maintained up to heating temperatures of more than $600^{\circ} \mathrm{C}$.

\section{References}

1. Yu.V. Kal'ner, Met. Sci. and Heat Treat. of Met., 4, 50 (1988)

2. M.Moradi, M.K. Moghadam, M.Kazazi, Optik, 178(2), 614 (2019)

3. Yu.N. Petrov, Defects and diffusion-free transformation in steel (1978)

4. M.Sinha, B.Syed, A.Karmakar, S.Ghosh, Materials Sci. and Eng.: A, 787(10), 139519 (2020)

5. A.N. Bekrenev, D.M. Gureev, S.I. Mednikov, Phys. and Chem. of Material Processing, 6, 107 (1989)

6. M.Katancik, S.Mirzababaei, M,Ghayoor, S.Pasebani, J. of Alloys and Compounds, 849(12), 156319 (2020)

7. T.Wang, J.Du, F.Liu, Materialia, 12(8), 100800 (2020)

8. I.A. Tananko, Met. Sci. and Heat Treat. of Met., 10, 2 (1983)

9. M.I. Gol'dshtejn, Dispersion hardening of steel (1979)

10. A. Ramar, R. Schäublin, J. of Nucl. Materials, 432(1), 323 (2013)

11. M.V. Belous, V.T. Cherepin, M.A. Vasiliev, Transformations during tempering of steel (1973)

12. W.Li, M.Cai, D.Wang, J.Zhang, S.Zhao, P.Shao, Materials Sci. and Eng.: A, 9(2), 410 (2017)

13. A.G. Rahshtadt, O.M. Hovova, New processes of alloy aging (1988)

14. V.N. Gridnev, Yu. N. Petrov, Met. Phys. and Met. Sci., 22(2), 215 (1966)

15. A.Kwiatkowski da Silva, G.Inden, A.Kumar, D.Ponge, B.Gault, D.Raabe, Acta Materialia, 147(1), 165 (2018)

16. Yu.I. Ustinovshchikov, Met. Phys. and Met. Sci., 41(1), 99 (1978)

17. F.Peng, Y.Xu, D.Han, X.Gu, Materials \& Design, 183(5), 108183 (2019)

18. E.Virtanen, C.J.Van Tyne, B.S.Levy, G.Brada, J. of Materials Processing Techn., 213(8), 1364 (2013)

19. A.V. Brover, News of High. Educat. Inst. Ferr. Met., 6, 30 (2006) 